\title{
GIS-modeling of Lake Onego Shoreline in the Holocene and Late Pleistocene
}

\author{
Mikhail Zobkov $^{1}$, Aleksey Tarasovi, ${ }^{1,}$, Dmitry Subetto ${ }^{1}$, Maksim Potakhin ${ }^{1}$ \\ ${ }^{1}$ Northern Water Problems Institute, Karelian Research Centre of RAS. Address: A. Nevskogo Avenue 50, \\ Petrozavodsk, Republic of Karelia, Russia, \\ ${ }^{2}$ Institute of Linguistics, Literature and History, Karelian Research Centre of RAS. Address: Pushkinskaya street \\ 11, Petrozavodsk, Republic of Karelia, Russia
}

\begin{abstract}
The application of GIS software for reconstruction of Lake Onego shoreline in the Holocene and the Late Pleistocene presented. Reconstruction was originated from the ideas of the Lake Onego depression deglaciation model proposed by I. Demidov [1] and the data of E. Deviatova [2] concerning Lake Onego depression isostatic uplift in the Holocene. ArcGIS software was used to perform GIS-modelling which was based on the original digital elevation model of the lakebed and its watershed. Twelve digital paleogeographic maps were developed as a result. Paleogeographic maps were verified by hand-drawn images of I. Demidov and E. Deviatova and by matching the lake shoreline and the position of archeological sites. Maps are available on-line in the electronic form [3]. The surface area of the Lake was determined at different stages of its development. The quantitative data obtained in this study is valuable for estimation of the lake volumes and the rates of discharge in the past.
\end{abstract}

Keywords: GIS-modeling, Holocene, Lake Onego, Late Pleistocene.

\section{INTRODUCTION}

Geographic information system (GIS) is valuable tool for reconstructing natural circumstances of the past. Together with digital elevation models (DEM) and paleolimnological and paleoclimatic research data GIS software enables to reconstruct major landforms in a high quality level $[4 ; 5 ; 6]$. Nevertheless, until now these methods were not applied to assess the process of Lake Onego development.

Lake Onego is the second largest lake in Europe with a surface area approximately ten thousand square kilometers. The Lake is located on the border between crystalline rocks of the Fennoscandian Shield and sedimentary rocks of the East European Platform. The lake depression was covered with glacial streams or proglacial lakes during the Pleistocene Scandinavian glaciations [7].

Currently there are several models of the Lake development in the Late Pleistocene and the Holocene $[8 ; 9 ; 10 ; 11 ; 1]$. These models give various estimation of glacioisostatic uplift of the lake shores, lake dimensions and water levels. A contemporary model of I. Demidov $[1 ; 10]$ was accepted as a basic model of the lake depression deglaciation. It includes six main stages of the lake depression development in the Late Pleistocene.

Geologist E. Deviatova in collaboration with archeologists V. Filatova, N. Lobanova, U. Savateev and A. Shuravlev $[2 ; 12 ; 13 ; 14]$ carried out extensive paleogeography studies of Lake Onego shoreline position in the Holocene period. The general evolution patterns of lake, relief, vegetation and climate with their connection with human settling activities were considered. The studies were conducted on several key locations where wellknown archeological sites were densely situated.

Glacioisostatic uplift data, published by I. Demidov [1; 11] and E. Deviatova [2; 12; 14] were assimilated to develop the model of Lake Onego development in the Holocene and the Late Pleistocene by GIS-software.

\section{II.MATERIALS AND METHODS}

The studied area lies in North-West part of Russian Federation and covers $570 \mathrm{~km}$ from North to South and $502 \mathrm{~km}$ from West to East (Fig.1).

The DEM developed by J. Ferranti [15] with spatial resolution three arc seconds was used as a source of watershed elevation data. This is the first freeware global elevation model with spatial resolution less than $100 \mathrm{~m}$ with coverage of the studied region. It is based on ASTER GDEM, USGS STRM DEM and topographic maps data. The DEM was converted to UTM WGS 84 zone $36 \mathrm{~N}$ projection (EPSG: 32636), and the same projection was used for other mapping features.

The DEM of lake depression was developed by using GIS Surfer software and was based on depth measurements, obtained from navigation charts of Lake Onego and the Svir River [16]. The lake depression DEM was led to sea level (SL) and combined with watershed elevation DEM. Thus, the http://dx.doi.org/10.17770/etr2017vol1.2541 
present-day DEM of lake watershed and its depression was obtained.

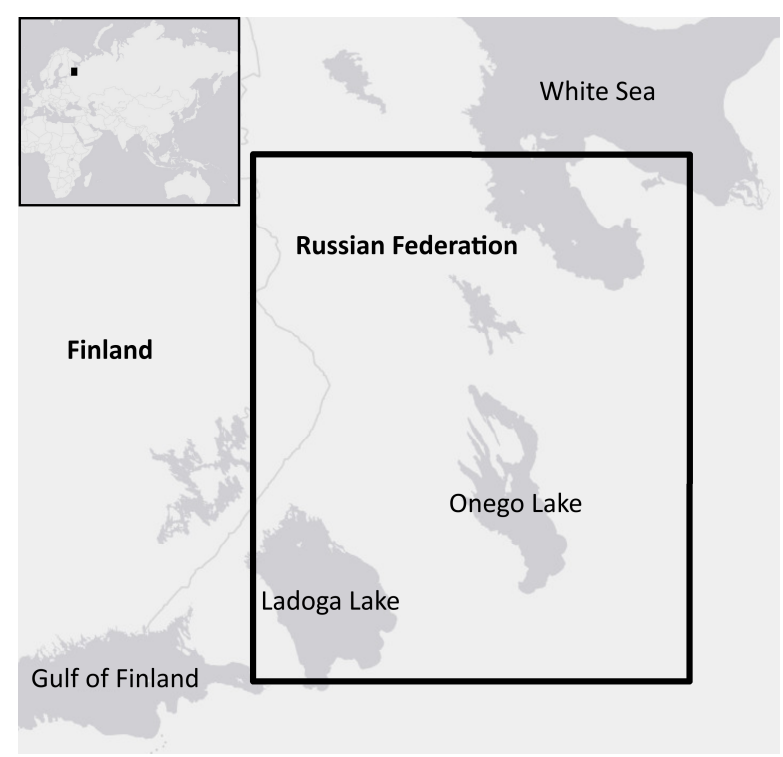

Fig. 1. Studied region location

The Earth's crust was flexed in the studied region because of considerable pressure going out from overlaid glacial shields. Later, when glacial shields were melting the area begun to suffer the compensational glacioisostatic uplift, which increased seismic activity and migration of the lake shoreline position. The highest uplift took place at the North shore of the lake because of considerably stronger glacial shield cover. Thus, the tilt of lake depression was around $30 \mathrm{~m}$ per $100 \mathrm{~km}$ of length $13300 \mathrm{yrs}$ BP, 12300 yrs BP - $26 \mathrm{~m}$, and $11000 \mathrm{yrs}$ BP it was $18 \mathrm{~m}$ [1]. By this reason, the Earth's crust uplift must be taken into account during the shoreline reconstructions.

The glacioisostatic uplift raster was defined to transform the present-day DEM to the paleo-DEM. The glacioisostatic uplift data of $[2 ; 12 ; 14]$ and [17] was used for the Holocen period and the data $[1 ; 11]$ was used for the Late Pleistocene period. The present day water level $(33 \mathrm{~m} \mathrm{SL})$ was subtracted from glacioisostatic uplift elevation mark (SL) of each data point in relevant period. As a result, the glacioisostatic uplift raster was calculated by means of 3D interpolation with a first order polynomial. The Surfer software was used for this purpose. Although the dynamic of Earth's crust galcioisostatic uplift 14 500-12 300 yrs BP was weak, the tilt of depression 13300 yrs BP was accounted for entire the Late Pleistocene. To take into account the lake level change in other stages in the Late Pleistocene the water level was corrected by its difference between 13300 yrs BP and the target stage. In the Holocene, glacioisostatic uplift of the Earth's crust had the main influence on the water level variation. Thus, glacioisostatic uplift rasters were calculated for minimum and maximum levels of every target periods.

On the next stage, the glacioisostatic uplift raster was subtracted from present-day DEM (Fig. 2) and the paleolake shoreline was established as a $(33 \pm \Delta \mathrm{h})$ $\mathrm{m}$ contour line. Where the $\Delta \mathrm{h}$ value is an average cumulative vertical error, occurred during DEM interpolation, elevation measurements, glacioisostatic uplift determination and raster interpolation. Average DEM error was calculated by using mean-square deviation between DEM values and topographic map elevation marks. Raster interpolation error was estimated as mean-square deviation between elevation marks and interpolated values at the same positions. Other errors were obtained from primary data sources, where they were mentioned. The map algebra and geo referenced calculations were implemented with the ArcGIS 10.2.2 with Spatial Analysis package.

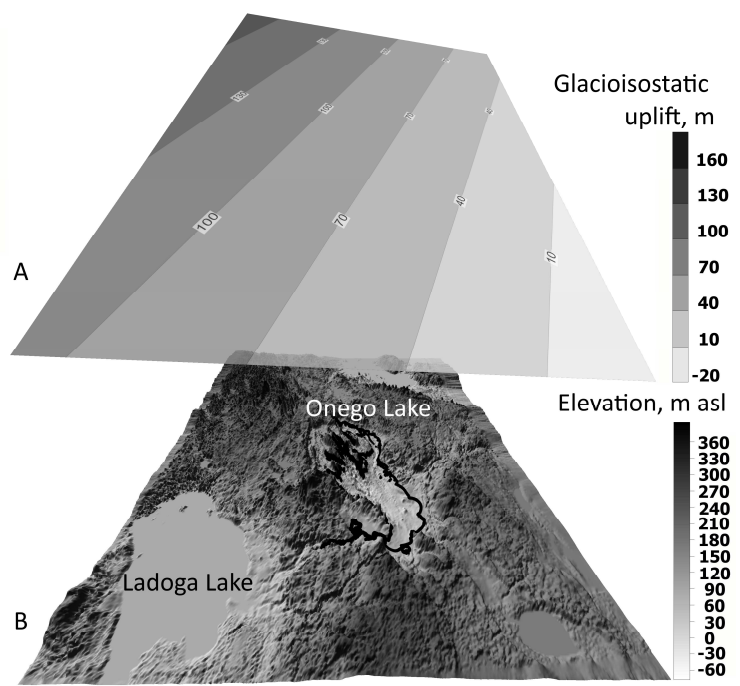

Fig. 2. Glacioisostatic uplift raster (A) and present day DEM (B).

Paleogeographic maps were verified in two ways. The first one was implemented by comparison of maps with hand-drawn images of I. Demidov $[1 ; 7]$ and E. Deviatova [2; 12; 13; 14]. Shoreline contours and island sizes were compared. The second way of verification was carried out by matching the lake shoreline with a position of archeological sites.

Mutual position of the shoreline for each reconstructed period and archeological sites dated in this period were considered in connection to each other. The proximity of the fresh water sources was required for human settling during the Stone Age and the Early Metal periods with hunting and fishingbased economies. Considering this, we may suppose that archeological sites had to be situated on the shore, not far from the reconstructed shoreline. For this purpose, the data of 130 archeological sites position with carbon dating was used. 


\section{RESULTS AND DISCUSSION}

DEM vertical error

The heights of the developed DEM were observed to be in average $1.65 \mathrm{~m}$ lower, than elevation marks of the geodetic control net. The standard deviation was $5.89 \mathrm{~m}$. Confident interval lies in a range from 1.1 to $-2.2 \mathrm{~m}$ with $\alpha=0.05$.

\section{Interpolation error}

Determination coefficients for polynomials interpolated vary significantly from 0.18 to 0.99 , and were 0.76 in average. The lowest coefficients $(0.18$, $0.34)$ were observed for the latest climatic period (SA) where values of glacioisistatic uplift were nearly the same as the mean DEM error. In any case, low values of determination coefficients were balanced by consideration of interpolation errors, which were varied from $\pm 0.7 \mathrm{~m}$ for $\mathrm{SA}$ up to $\pm 2.5 \mathrm{~m}$ for DR.

\section{Paleogeographycal verification}

The paleoreconstructions are available online [3].

Paleogeographic maps were verified by handdrawn images of I. Demidov and E. Deviatova. Compared with hand drawings of I. Demidov, our maps were detailed considerably and had strict geographic reference. On the contrary, in comparison with E. Deviatova reconstructions, our maps roughed the fine relief forms. The main reason for this was a higher vertical error of DEM used. Even so the common shoreline configuration and dimensions of large islands conforms to sketches and descriptions of E. Deviatova. Considering this, the reconstruction presented a new data about shoreline position on the unstudied area, which covers most part of the lake shoreline.

\section{Archeological verification}

Substantially in all the cases, where archeological sites had strict GPS reference and dating, they were situated on the shore or within a range of water level fluctuation. In a few cases, archeological sites were positioned on the lake surface, but not far than $50 \mathrm{~m}$ from lowest shoreline. That was due to the horizontal DEM error, because this type of error was not taken into account during vertical error estimation. Horizontal DEM error was assumed as a $1 / 2$ of DEM mesh size and lies around $45 \mathrm{~m}$ [18].

\section{Morphometry of lake}

We used the developed paleogeographic maps to calculate the morphometric characteristics of Lake Onego in the Past (Table).

In the 14500 yrs BP the area of the lake was the smallest, due to considerable glacial shield cover over the lake depression. Later, when the glacial shield melted, the water surface increased up to historical maximum in 13300 yrs BP (Fig.3). In 13200 yrs BP the lake acquired a new threshold for runoff to the White Sea basin, and the lake level dropped considerably. At 12400 yrs BP the ice-dammed lake attained another runoff threshold across the northern part of the Onego-Ladoga water divide and the lake level dropped again.

Table

Surface area of Lake Onego in the Holocene and the Late Pleistocene. Confident interval with $\alpha=0.05$

\begin{tabular}{r|l}
\hline Yrs BP $($ Climatic period $)$ & \multicolumn{1}{c}{ Area, $\mathrm{km}^{2}$} \\
\hline $14500(\mathrm{BL})$ & $2711 \pm 64$ \\
\hline $14000\left(\mathrm{DR}_{2}\right)$ & $14785 \pm 684$ \\
\hline $13300(\mathrm{AL})$ & $32328 \pm 1484$ \\
\hline $13200\left(\mathrm{AL}-\mathrm{DR}_{3}\right)$ & $24879 \pm 1078$ \\
\hline $12400\left(\mathrm{DR}_{3}\right)$ & $22590 \pm 1169$ \\
\hline $\left.12300(\mathrm{DR})_{3}\right)$ & $21484 \pm 1149$ \\
\hline $12300-10300(\mathrm{DR})$ & $17728 \pm 1040$ \\
\hline $10300-9300(\mathrm{~PB})$ & $15562 \pm 1213$ \\
\hline $9300-8000 \mathrm{BO})$ & $13018 \pm 1231$ \\
\hline $8000-4700(\mathrm{AT})$ & $11195 \pm 1157$ \\
\hline $4700-2500(\mathrm{SB})$ & $10634 \pm 764$ \\
\hline $2500-800(\mathrm{SA})$ & $9598 \pm 273$ \\
\hline
\end{tabular}

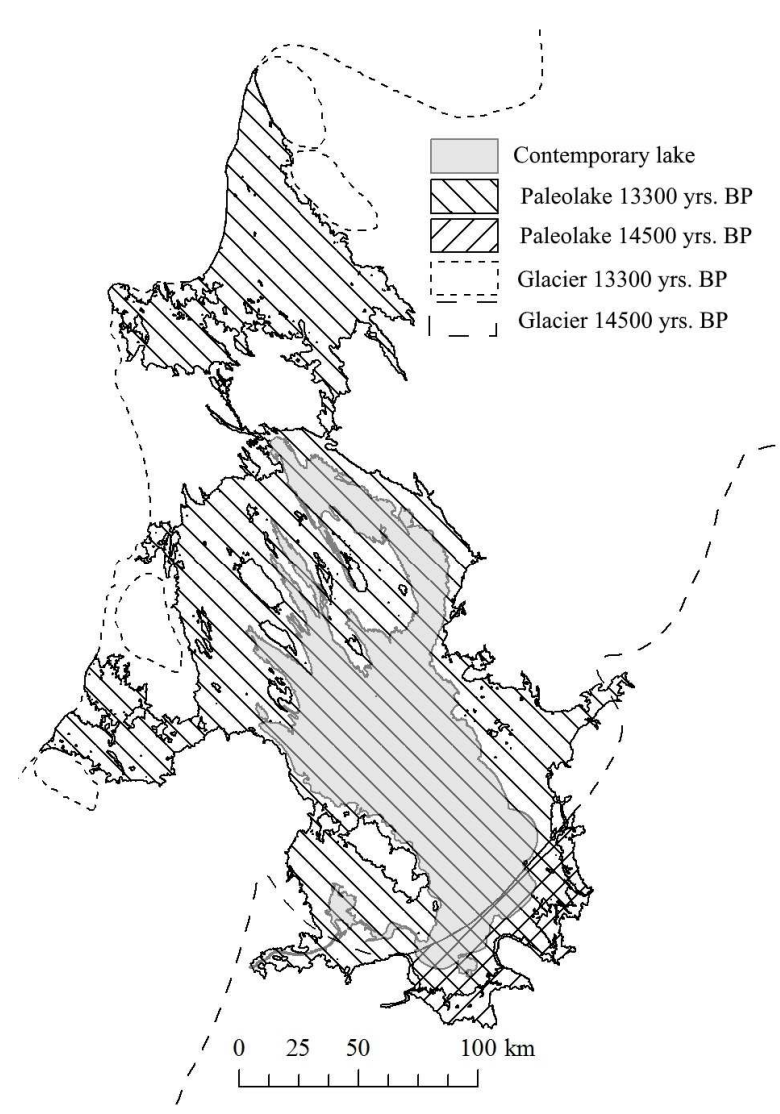

Fig. 3. The smallest and the largest stages of Lake Onego development. 
At the end of the Younger Dryas 12 400-12 300 yrs BP, when the drainage pathway via the Svir River to Lake Ladoga was reopened, another regression happened. By that time, the lake had already lost its connection to the glacier, which had retreated westwards. Later the glacioisostatic uplift activities play the main role in lake shoreline formation. The area of the lake surface was reduced during the following climatic periods.

\section{CONCLUSION}

GIS-based reconstructions of Lake Onego development in the Holoceneand the Late Pleistocene were presented in the article. Reconstructions were originated from the ideas of the Lake Onego depression deglaciation model proposed by I. Demidov and the data of E. Deviatova concerning Lake Onego depression isostatic uplift in the Holocene. GIS-modeling was performed using ArcGIS software on the base of original digital elevation model of the lakebed and its watershed. The reconstructions for all periods were unified, had spatial resolution $90 \mathrm{~m}$ and a strict geographic conjunction. Twelve digital paleogeographic maps were developed as a result. The produced maps are available on-line. Paleogeographic maps were verified by using hand-drawing images of I. Demidovand E. Deviatova and by matching lake shoreline with a position of archeological sites.

The Holocene period reconstructions based on I. Demidov data have been found to be more precise than previous hand drawn images. Our reconstructions of the Late Pleistocene period based on data E. Deviatova were likely to rough the fine relief forms. Nevertheless, they have been produced in a global scale for the whole lake surface, which was not conducted earlier.

Based on our reconstructions the area of the lake surface was determined at different stages of its development. The quantitative data obtained in this study is valuable for estimation of the lake volumes and the rates of discharge in the past. Awareness of the lake's shoreline position allows determining areas, where human settling was possible, and increases our chances of discovering new archaeological sites.

\section{ACKNOWLEDGMENTS}

The study has been financially supported by the Russian Science Foundation (\#14-17-00766) \& the Russian Foundation for Basic Research (\#16-0500727).

\section{REFERENCES}

[1] I. N. Demidov, "On a maximum stage in the evolution of periglacial Lake Onega, variations in its water level and glacioisostatic shore uplift of the shore in the Late Glacial Period" in Geology and mineral resources of Karelia, 2006, vol. 9, pp. 171-182 (in Russian).

[2] E. I. Deviatova, The natural environment and its changes during the Holocene (the northern and central coast of Lake Onega). Petrozavodsk, 1986, 108 p (in Russian).

[3] D. Subetto, M. Zobkov, M. Potakhin, A. Tarasov, Lake Onego Development GIS-reconstruction in the Late-Glacial Period, January 2017. [Online]. http://www.arcgis.com/apps/ MapJournal/index.html?appid=47d76ba2004e463d96eba1d8a 1825fe1. [Accessed February 15, 2017], (in Russian).

[4] M. Jakobsson, S. Björck, G. Alm, T. Andrén, G. Lindeberg, N.-O. Svensson, "Reconstructing the Younger Dryas ice dammed lake in the Baltic Basin: bathymetry, area and volume" in Global and Planetary Change, 2007, vol. 57, pp. 355-370.

[5] J. Vassiljev, L. Saarse, "Timing of the Baltic Ice Lake in the eastern Baltic" in Bulletin of the Geological Society of Finland, 2013, vol. 85, pp. 9-18.

[6] H.-L. Habicht, A. Rosentau, A. Joeleht, A. Heinsalu, A. Kriiska, M. Kohv, T. Hang, R. Aunap, "GIS-based multiproxy coastline reconstruction of the eastern Gulf of Riga, Baltic Sea, during the Stone Age" in Bores, 2017, vol. 43(1), pp. 83-99.

[7] Lake Onego. Atlas / N. N. Filatov (eds.), Petrozavodsk, 2010, 151 p. (in Russian).

[8] G. S. Biske, G. T. Lak, A. D. Lukashov et al., Structure and history of the Onega Lake depression. Petrozavodsk, 1971, 74 p, (in Russian).

[9] D. D. Kvasov, "The origin of Lake Onego depression" in Paleolimnology of Lake Onego. Leningrad, 1976, pp. 7-40 (in Russian).

[10] M. Saarnisto, T. Gronlund, I. Ekman, "Lateglacial of Lake Onega - contribution to the history of the eastern Baltic basin" in Quaternary International, 1995, vol. 27, pp. 111120.

[11] I. N. Demidov, "Degradation of the Late Valdai Glaciation in the basin of Lake Onega" in Geology and mineral resources of Karelia, 2005, vol. 8, pp. 134-142 (in Russian).

[12] E. I. Deviatova, "Paleogeography of Sheltozero settlements" in Archeological sites of Onego Lake basin. Petrozavodsk, 1984, pp. 25-47(in Russian).

[13] E. I. Deviatova, "Paleogeography and human settlement of Karelia" in Ancient Karelian settlements. Petrozavodsk, 1988, pp. 7-18 (in Russian)

[14] E. I. Deviatova, N. V. Lobanova, V. F. Filatova, Paleogeography of Archeological Monuments at Pindushi. Petrozavodsk, 1987, 60 p. (in Russian).

[15] J. Ferranti, Digital elevation data, January 2017. [Online]. Available: http://www.viewfinderpanoramas.org/. [Accessed February 15, 2017].

[16] Lake Onego and River Svir. Navigation charts, Moscow, 1988 (in Russian).

[17] G. A. Elina, A. D. Lukashov, T. K. Yurkovskaya, Late glacial and Holocene palaeovegetation and palaeogeography of the Eastern Fennoscandia. Petrozavodsk, 2000, 240 p. (in Russian).

[18] E. Rodriguez, C. S. Morris, J. E. Belz, "A Global Assessment of the SRTM Performance" in Photogrammetric Engineering and Remote Sensing, 2006, vol. 72(3), pp. 249-260. 